\title{
The Efficacy of Various Anti- Rabies Vaccines in Dog Bite Victims in Tuticorin and Bangalore, India
}

\author{
Gifty Immanuel $^{1,2 *}$ and S. Shanmugavel ${ }^{3}$ \\ ${ }^{1}$ Infectious Diseases Physician, CSI Hospital Bangalore-560005, India \\ ${ }^{2}$ Center for AIDS and Antiviral Research, Tuticorin-628003, India \\ ${ }^{3}$ Department of Zoology, V.O.C College, Tuticorin-628008, Tamilnadu, India \\ *Corresponding author
}

\begin{tabular}{|c|c|}
\hline & A B S T R A C T \\
\hline & \multirow{4}{*}{$\begin{array}{l}\text { To determine the most effective vaccine against rabies infection in the vaccines who took } \\
\text { different types of vaccines for dog bite in rural areas of Tuticorin and urban areas of } \\
\text { Bangalore. All the blood samples collected post intramuscular vaccinations were tested by } \\
\text { RFFIT (Rapid Fluorescent Focus Inhibition Test). A total of } 100 \text { blood samples from } \\
\text { vaccines were collected twice on days (14, 28) from volunteers in the period between } \\
2013-2016 \text {. A cohort of } 25 \text { vaccinees were assigned to four different types of rabies } \\
\text { vaccines groups PCEV (Rabipur, India), PVRV (Verorab, France), HDCV (Mireux, } \\
\text { France), PDEC (Vaxirab, India). Responses to four commercially available vaccines in } \\
\text { India were compared namely PCEC, HDCV, PVRV, PDEV. Although all available types } \\
\text { of vaccines had elicited the required minimum rabies virus neutralizing antibody RVNA } \\
\text { (titers above } 0.5 \text { IU), the following vaccine Purified Vero Cell Vaccine PVRV elicited the } \\
\text { maximum neutralizing antiviral antibodies in the vaccine recipients (vaccinees). However, } \\
\text { no significant differences in the quantum of RVNA were observed in all groups. }\end{array}$} \\
\hline $\begin{array}{l}\text { Rabies, Vaccinees, } \\
\text { Zoonosis, } \\
\text { Immunity, } \\
\text { Prophylaxis, } \\
\text { Neutralizing } \\
\text { antibody. }\end{array}$ & \\
\hline Article Info & \\
\hline $\begin{array}{l}\text { Accepted: } \\
\text { 20 March } 2017 \\
\text { Available Online: } \\
10 \text { April } 2017\end{array}$ & \\
\hline
\end{tabular}

\section{Introduction}

Rabies, a neglected tropical viral disease accounts for a huge public health burden in developing countries (Hampson et al., 2015). Rabies is a zoonotic disease transmitted by the bite of a rabid dog. As a neglected disease, rabies largely remains under reported and under diagnosed. According to 1985 survey nearly 15 million people received dog bites in India (Sudarshan et al., 2004). Stray dogs and uncontrolled dog population have accounted for it. Dutta (1999) report 20,000 fatalities annually in India due to rabies, globally India contributes to $36 \%$ of the total rabies disease burden. However, the annual incidence has been decreasing due to improved preventive measures.

Human rabies following an animal bite can be prevented by vaccination or (PEP) post exposure prophylaxis (Hemachuda et al., 2002). Without vaccination, rabies is a uniformly fatal disease. Since, there is no effective drug or a proven treatment against rabies, vaccination forms the key prevention method for the millions at risk of rabies.

However, different types of vaccines are commercially available in India, and it is 
imperative that we understand which among these vaccines elicits the maximum rabies virus neutralizing antibodies (RVNA) against the rabies virus. Such information could greatly aid physicians and health care personal in deciding the most effective vaccine in preventing rabies. Therefore, the present study was conducted in two sites Tuticorin (rural) and Bangalore (urban) to get the data on the most efficacious vaccine amongst the currently available vaccines against rabies. This study will enable the evaluation of the most immunogenic vaccine against rabies.

Globally, only five types of vaccines against rabies are being used (Plotkin, 2005). The nervous tissue vaccines are no longer used to due adverse reactions and a futuristic DNA based recombinant rabies vaccine is not fully available. Currently, the following are the four commercially available vaccines in India, Purified Chick Embryo Cell (PCEC) vaccine, Human Diploid Cell Vaccine (HDCV), Purified Vero Cell Vaccine (PVRV), Purified Duck Embryo Vaccine (PDEV).

\section{Materials and Methods}

\section{Study population}

The study was conducted from 2013 till 2016 in two sites. Vaccinees that had undergone different types of anti-rabies vaccines for dog bites were chosen in a random order and assigned to four different vaccine groups of 25 each. $1^{\text {st }}$ site- (Tuticorin, Tamilnadu and Tuticorin, headquarters of Tuticorin District, $90 \mathrm{~km}^{2}$ has a population of 440,760) represents rural population. $2^{\text {nd }}$ site (Bangalore capital of Karnataka State with a $700 \mathrm{~km}^{2}$ has a population of 9 million) represents urban population. The study population was in the age range of 15 to 75 years.

\section{Sample collection}

Blood samples were collected (day 14, day 28) after the last in the series of anti-rabies vaccination to ensure full antibody response to the vaccine. Venous bloods from the arms were collected with complete aseptic precautions using plain vacutainers. The serum was separated under centrifugation. The serum samples were refrigerated and sent to Neuro-virology laboratory for RFFIT test for rabies virus neutralizing antibody study. The samples were collectively tested.

\section{Serum examination}

Blood samples were stored under refrigeration and later serum separated. 1. $2 \mathrm{~mL}$ serum was tested with RFFIT (Rapid Fluorescent Focus Inhibition Test).

\section{Statistical analysis}

$\chi 2$ test using Two-way Contingency Table has been applied to test the level of significance.

\section{Results and Discussion}

A total of 100 healthy Indian individuals who were attending two dog bite clinics at Tuticorin and Bangalore were assigned to four groups based on the type of vaccination received. The Purified Chick Embryo Cell (PCEC) vaccine Group, Human Diploid Cell Vaccine Group (HDCV), Purified Vero Cell (PVRV) Vaccine Group and the Purified Duck Embryo (PDEV) Vaccine Group. At the time of enrollment for the study, there weren't any significant differences in weight, age and gender between the four groups. All the participants provided blood samples after the last in the series of vaccination. All vaccines were well tolerated and there was no significant adverse reaction, except pain in the injection site in $(1 \%)$ of the vaccinees in the total pool. A similar study also found these 
vaccines largely safe and no major adverse reactions reported among the vaccinees (Ashwathnarayana et al., 2010) .Blood withdrawals were done on days $(14,28)$ for all four groups. RVNA were measured for all four groups on day (14 and 28).

Table 1 shows the different geometric mean titers (GMT) of rabies virus neutralizing antibodies (RVNA) obtained for each type of vaccine used on day 14 after the last vaccination. All subjects in this study had reached rabies virus neutralizing antibodies (RVNA) of more than the W.H.O recommended $0.5 \mathrm{IU}$ by the end of (day 14).
This affords protection against pathogenesis of rabies infection.

However, among the four different types of vaccines studied, that is Purified Chick Embryo Cell (PCEC) vaccine, Human Diploid Cell Vaccine (HDCV), Purified Vero Cell Vaccine (PVRV), Purified Duck Embryo Vaccine (PDEV), the PVRV had the maximum GMT of rabies virus neutralizing antibodies (8.23 I.U) followed by PCEC with a $14^{\text {th }}$ day RVNA of (7.1 I.U). We did not observe much variation between the rural and urban population.

Table.1 Comparison of RVNA for four different vaccines in a cohort of 100 vaccines

\begin{tabular}{|c|c|c|c|c|c|c|}
\hline $\begin{array}{c}14^{\text {th }} \text { Day after the last } \\
\text { vaccination }\end{array}$ & PCEC & HDCV & PVRV & PDEV & $\begin{array}{c}\text { Test } \\
\text { Method }\end{array}$ & $\begin{array}{c}\text { Sample } \\
\text { Source }\end{array}$ \\
\hline $\begin{array}{c}\text { Rabies Virus Neutralizing } \\
\text { Antibody Levels (RVNA) } \\
\text { Geometric Mean Titers } \\
\text { (GMT) RVNA level for a } \\
\text { cohort (of 25 vacinees) per } \\
\text { Vaccine group }\end{array}$ & 7.1 I.U & 6.55 I.U & 8.23 I.U & 6.23 I.U & $\begin{array}{c}\text { FFFIT) } \\
\text { Fapid } \\
\text { Forescent } \\
\text { Focus } \\
\text { Inhibition }\end{array}$ & Serum \\
\hline
\end{tabular}

*PCEC-Purified Chick Embryo Cell Vaccine, HDCV- Human Diploid Cell Vaccine, PVRV-Purified Vero Cell Vaccine, PDEV-Purified Duck Embryo Vaccine.

\# WHO Rabies Virus Neutralizing Antibody Level - 0.5 IU.

* RFFIT- Rapid Fluorescent Focus Inhibition, RVNA - Rabies Virus Neutralizing Antibody Level GMT- Geometric Mean Titers of RVNA obtained at day 14

Table.2 Comparison of RVNA for four different vaccines in a cohort of 100 vaccines

\begin{tabular}{|c|c|c|c|c|c|c|}
\hline $\begin{array}{c}28^{\text {th }} \text { Day after the last } \\
\text { vaccination }\end{array}$ & PCEC & HDCV & PVRV & PDEV & $\begin{array}{c}\text { Test } \\
\text { Method }\end{array}$ & $\begin{array}{c}\text { Sample } \\
\text { Source }\end{array}$ \\
\hline $\begin{array}{c}\text { Rabies Virus Neutralizing } \\
\text { Antibody Levels (RVNA) } \\
\text { Geometric Mean Titers (GMT) } \\
\begin{array}{c}\text { RVNA level for a cohort (of 25 } \\
\text { vaccinees) per Vaccine group }\end{array}\end{array}$ & 17.2 I.U & 16.1 I.U & 18.3 I.U & 15.99 I.U & $\begin{array}{c}\text { (RFFIT) } \\
\text { Rapid } \\
\text { Fluorescent } \\
\text { Focus } \\
\text { Inhibition }\end{array}$ & Serum \\
\hline
\end{tabular}

*PCEC-Purified Chick Embryo Cell Vaccine, HDCV- Human Diploid Cell Vaccine, PVRV-Purified Vero Cell

Vaccine, PDEV-Purified Duck Embryo Vaccine.

\# WHO Rabies Virus Neutralizing Antibody Level - 0.5 IU.

* RFFIT- Rapid Fluorescent Focus Inhibition, RVNA - Rabies Virus Neutralizing Antibody Level GMT- Geometric Mean Titers of RVNA obtained at day 28. 
Table. 3 2 Calculations using two-way contingency table

\begin{tabular}{|c|c|c|c|c|c|}
\hline \multirow{2}{*}{ Day } & \multicolumn{4}{|c|}{ (GMT) RVNA Titers } & \multirow{2}{*}{ Total } \\
\hline & PCEC & HDCV & PVRV & PDEV & \\
\hline Day 14 & $\begin{array}{c}7 \\
7.14 \\
(0.00)\end{array}$ & $\begin{array}{c}6 \\
6.65 \\
(0.00)\end{array}$ & $\begin{array}{c}8 \\
7.79 \\
(0.02)\end{array}$ & $\begin{array}{c}6 \\
6.53 \\
(0.01)\end{array}$ & 28 \\
\hline Day 28 & $\begin{array}{c}17 \\
17.16 \\
(0.00)\end{array}$ & $\begin{array}{c}16 \\
16.00 \\
(0.00)\end{array}$ & $\begin{array}{c}18 \\
18.74 \\
(0.01)\end{array}$ & $\begin{array}{c}15 \\
15.69 \\
(0.01)\end{array}$ & 67 \\
\hline & 24 & 22 & 26 & 22 & 95 \\
\hline
\end{tabular}

Table 2 shows the levels of RVNA obtained on day 28 for the four vaccines under study. There weren't any significant differences between the RVNA levels of all the vaccines. However, PVRV showed a consistently higher response rate of (18.3 I.U), while PCEC had the second highest level of (17.2 I.U). Both PDEV and HDCV remained lower in their RVNA level (15.99 I.U) and (16.11) respectively.

Table 3 represents $\chi^{2}$ Calculations using Two-way Contingency Table. This was used to study GMT levels of RVNAs of the four groups of vaccines on day 14 and day 28. PCEC and PVRV had a total of (24) and (26) respectively.

Rabies being a uniformly fatal disease, vaccination remains a mainstay. However, despite rabies being a vaccine preventable disease, it accounts for significant mortality (Schneider et al., 2007). Though all four vaccines are commercially available; there is great variation on the choice of vaccine, among dog bite victims. The reason for such variation is beyond the scope of this study. However, a base line data on the RVNA generation after each type of vaccines would help health care personal make vaccine choices based on the vaccines co-morbidities and immune status.
A meta-analysis by (Sudershan et al., 2010) involving 1100 subjects in 19 studies using GMT of RVNA to measure the response to antigenic load on days (14 and 28) using RFFIT, found a similar pattern of RVNA titers for PCEC, PVRV and HDCV. However, this meta-analysis did not include PDEC. While a separate multi-centric study in India by (Mahendra et al., 2010) at the same period of time found PDEC equally immunogenic and safe. The GMT of RVNA on day 14 and 30 remained (10 I.U and 15.88 I.U) respectively in this study. This largely coincided with our results for PDEC on days (14 and 28).

Though all vaccines used in this study were found to be non-inferior to one another, PVRV had produced the maximum rabies virus neutralizing antibodies on day $14^{\text {th }}$ and day 28. The significance of the findings has implications for poor vaccine responders, especially people in extremes of age and those with a compromised state of immunity. It is plausible that such a robust immune response with PVRV could compensate for the otherwise poor response seen in such groups. However, our study has limitations; it does not specifically address such poor responders to rabies vaccines. Further large scale studies needs to be done to substantiate this preliminary observation. 


\section{Acknowledgement}

Authors are thankful to late Dr. Madhusudhana NIMHANS Bangalore and the Hospital Staff at Tuticorin and Bangalore for their assistance and encouragement.

Conflict of interest statement - We declare that we have no conflict of interest.

\section{References}

Ashwathnarayana, D.H., Madhusudana, S.N., Sampath, G., Sathpathy, D.M., Mankeshwar, R., Ravish, H.H.S., Ullas, P.T., Behra, T.R., Sudarshan, M.K., Gangaboraiah, Shamanna, M. 2010. A comparative study on the safety and immunogenicity of purified duck embryo vaccine (PDEV, Vaxirab) with purified chick embryo cell vaccine (PCEC, Rabipur) and purified vero cell rabies vaccine (PVRV, Verorab). Vaccin 28: 148-151.

Chakradhar, S. 2015. Biting back: vaccine efforts redoubled as rabies deadline looms. Nat. Med., 21: 8-10.

Dutta, J.K. 1999. Human rabies in India: epidemiological features, management and current methods of prevention. Trop. Doct., 29: 196-201.

Hampson, K., Coudeville, L., Lembo, T., Sambo, M., Kieffer, A., Attlan, M. 2015. Estimating the Global Burden of Endemic Canine Rabies. PLoS Negl. Trop. Dis., 9(4): 101-371.
Hemachudha, T., Laothamatas, J., Rupprecht, C.E. 2002. Human rabies: a disease of complex neuropathogenetic mechanisms and diagnostic challenges. Lancet Neurol., 1(2): 101-9.

Mahendra, B.J., Madhusudana, S.N., Sampath, G., Datta, S.S., Ashwathnarayana, D.H., Venkatesh, G.M., Sudarshan, M.K., Bilugumba, G., Shamanna, M. 2010. Immunogenicity, safety and tolerance of a purified duck embryo vaccine (PDEV, VAXIRAB) for rabies post-exposure prophylaxis: results of a multicentric study in India. Hum. Vaccin., 6: 721-724.

Plotkin, S.A. 2005. Vaccines: Past, Present and Future: Historical Perspective. Nature Med., Supplement 11.

Sudarshan, M.K. 2004. Assessing burden of rabies in India. WHO sponsored national multi-centric rabies survey. Assoc. Prev. Control Rabies India J., 6: 44-5.

Sudarshan, M.K., Gangaboraiah, B., Ravish, H.S., Ashwath Narayana, D.H. 2010. Assessing the relationship between antigenicity and immunogenicity of human rabies vaccines when administered by intradermal route: Results of a meta analysis. Hum. Vaccin., 6: 562-5.

Schneider, M.C., Belotto, A., Ade, M.P. 2007. Current status of human rabies transmitted by dogs in Latin America. Cad Saude Publica, 23(9): 2049-2063.

\section{How to cite this article:}

Gifty Immanuel and Shanmugavel, S. 2017. The Efficacy of Various Anti- Rabies Vaccines in Dog Bite Victims in Tuticorin and Bangalore, India. Int.J.Curr.Microbiol.App.Sci. 6(4): 22982302. doi: https://doi.org/10.20546/ijcmas.2017.604.268 